\title{
Dynamic performance of a real-scale reinforced concrete building test under a corner-column failure scenario
}

\author{
Jose M. Adam $^{\mathrm{a}}$, Manuel Buitrago ${ }^{\mathrm{a}}$, Elisa Bertolesia ${ }^{\mathrm{a}}$ Juan Sagaseta $^{\mathrm{b}}$, Juan J. Moragues ${ }^{\mathrm{a}}$ \\ a'ICITECH, Universitat Politècnica de València. Camino de Vera s/n, 46022 Valencia, Spain \\ ${ }^{b}$ Department of Civil and Environmental Engineering, University of Surrey, GU2 7XH Guildford, UK \\ * Corresponding author. Tel.: +34 963877562; fax: +34 963877568. \\ E-mail address: joadmar@upv.es (J.M. Adam).
}

\section{Abstract}

The topic of robustness and progressive collapse of structures has attracted significant attention within the field of structural engineering recently. This is reflected by the rise in the number of scientific papers published in recent years as well as efforts in reviewing and developing codes for design. Although important numerical and experimental studies have been carried out to date simulating the sudden removal of columns to reproduce the possible consequences of an extreme event, most of these studies focus on subassembly systems and internal columns. Edge and corner columns are most vulnerable to accidental events. This paper gives the results of a test carried out on a purpose-built full-scale reinforced concrete building with a specially designed corner steel column used for the sudden column removal. The test was highly instrumented, involving 38 strain gauges, 38 displacement transducers and 2 accelerometers to monitor the vertical and lateral response. The results were used to analyse the dynamic performance of the structure after the sudden column removal as well as the alternative load paths (ALPs) mobilised during the test (i.e. flexural and Vierendeel action). The test showed a clear dynamic amplification of the strains and displacements (with high peaks); dynamic amplification factors (DAFs) were obtained accordingly. The load initially carried by the removed column was redistributed through the entire building system (not just the neighbouring columns). Tests on full-scale buildings, including the one described here, can be used to compile a database to validate codes and future numerical studies.

Keywords: Experimental study; Extreme events; Progressive collapse; Robustness; RC structures; Corner columns. 


\section{Introduction}

Interest on structural robustness and progressive collapse has risen significantly in the last twenty years [1] resulting into different research studies generally looking at testing of subassembly of structural systems and numerical work with different level of sophistication [25]. Extreme situations, also known as low-probability/high-consequence events, include, for example: natural disasters (tsunamis, hurricanes, floods, etc.) or man-made hazards (e.g. terrorist attacks, impacts or explosions). These events often cause local failure of some of the structural members that can trigger a progressive collapse, with an inherent risk to human lives and property. Some events with a high impact amongst the engineering community include the well-known Ronan Point Apartment Block (London, 1968), the A.P. Murrah Federal Building (Oklahoma, 1995), the World Trade Center Buildings (New York, 2001) or, more recently, the Achimota Melcom Shopping Centre (Acra, 2012), among others [6]. Events such as these have given rise to the renewed interest of the scientific community and the international standards-issuing authorities $[1,7,8]$ in reviewing design clauses for robustness for traditional and novel forms of construction.

The studies carried out in the past can be divided into two groups: a) those that aimed to quantify and study the possible outcomes of extreme events (i.e. threat-dependent approaches) $[9,10]$; and b) those that only attempted to minimise the consequences of a local failure, whatever its cause (i.e. threat-independent approaches) and avoid the failure spreading to other elements in the building $[5,11,12]$. Within this latter group, diverse numerical and experimental studies have analysed the structural response of buildings subjected to column removal as recommended in most current codes [13-15]. Although these studies included the possible causes of column failures, including internal [16-23], external [2,16,24-31] and corner columns (e.g. [32-34]), few studies have been done on corner column failures, even though these are the most vulnerable columns in the structure (e.g. to impact). Existing tests on corner column removal focused on subassemblies of frames or flat slab structures under monotonic loads applied by an actuator [29,32,33,35-41]. Only tests by Xiao et al. [42,43] and Zhao et al. [44,45] considered complete, 
but not full scale, structures and only the experimental study by Xiao et al.[42,43] was performed under a real sudden loss of a corner column.

The most novel contribution from the present study is the testing of a two-story RC building structure subjected to the sudden removal of a corner column with gravity loads defined in design codes corresponding to a prescribed accidental load combination $[13,14,46]$. It should be noted that tests in the literature were generally conceived to investigate the response to failure (including the activation of large deformations) and therefore gravity loads applied in the specimens were much higher than those specified in the building standards. Therefore the level of damage observed in such tests is often higher compared to that predicted in typical design situations. As discussed by Russel et al. [47] dynamic amplification is influenced by the level of damage which in turn depends on the stiffness and the level of gravity loading applied in the structure. Hence, it is debatable whether many of the tests in the literature are suitable to derive dynamic amplification factors which are consistent with design assumptions.

Based on the limitation of existing test data mentioned above, the main objective of the present work was to determine the dynamic performance of a full-scale RC building structure under a corner-column failure scenario with loads, geometry and mechanical properties reflecting design conditions. The second objective of this work was to analyse the test results to obtain a better understanding of the various alternative load paths (ALPs) developed in the structure; common tests on sub-assemblies can only mobilised a limited number of ALPs.

The paper is organized as follows: Section 1 includes the introduction, the aims and novel aspects of the study; Section 2 describes the main characteristics of the building used in the test as well as the main design considerations; Section 3 describes the test procedure and the instrumentation adopted to monitor the structure; Section 4 gives the time-history results (horizontal and vertical displacements, strains and accelerations) obtained during the test and describes the final state of the structure after the sudden removal of the corner-column; Section 5 analyses and discusses the results; while Section 6 summarises the main conclusions and outlines the possible direction of future lines of research. 


\section{Description of the building}

The study was carried out on a full-scale RC building structure, specially built for this purpose. Testing a full-scale specimen structure provides many benefits, since: 1) it allows certain aspects to be considered that would be impossible to reproduce in sub-assembly tests, (e.g. 3D effects, slab-column moment transfer, and the activation of different ALPs), 2) possible errors due to scaling down can be avoided, and 3) a comprehensive monitoring system can be used (including internal strain gauges at columns), which would be impossible to fit to an existing building. The building was designed according to Eurocode 2 [48] for a high occupancy building category (C1, C2 or C3) [49] with a dead load of $2 \mathrm{kN} / \mathrm{m}^{2}$ and a uniformly distributed live load of $3 \mathrm{kN} / \mathrm{m}^{2}$ for the first and second slabs. The building had two floors with a free storey height of $2.8 \mathrm{~m}$, four $5.0 \mathrm{~m}$ long squared bays, $20 \mathrm{~cm}$ thick flat slabs and $30 \mathrm{~cm}$ by $30 \mathrm{~cm}$ columns. Nominal cover of columns and slabs was defined as $30 \mathrm{~mm}$. The foundations consisted of isolated footings connected by $40 \mathrm{~cm}$ squared beams. Fig. 1 shows a 3D view of the building, together with a photo taken during its construction.
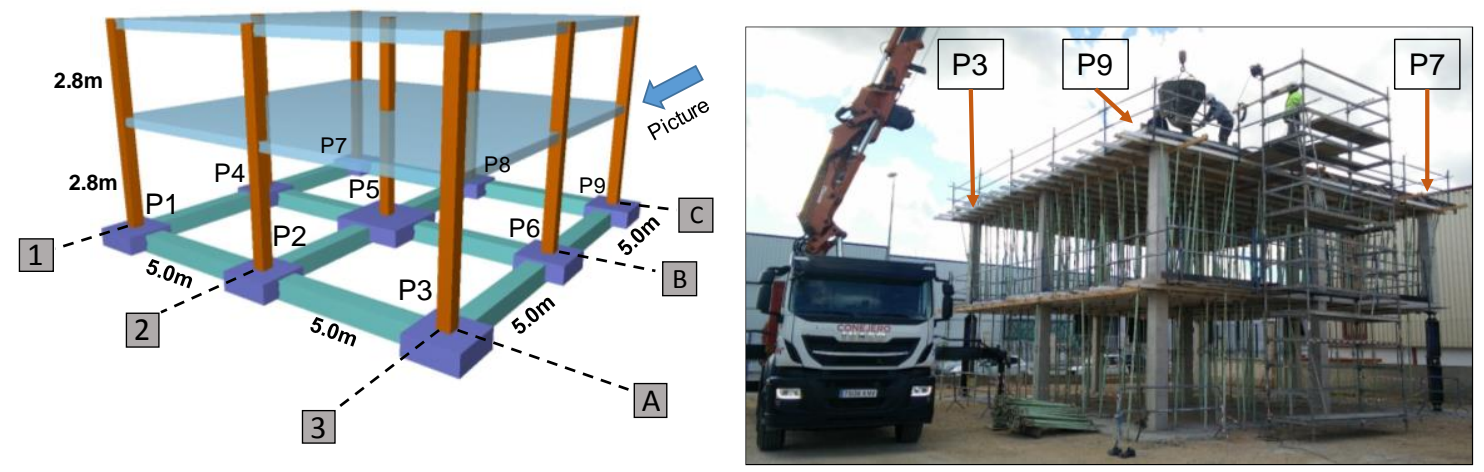

Fig. 1. 3D view of the building structure.

The building belongs to a consequence class 2a (Lower Risk Group) following Eurocode 1, Part 1-7 [15], but it was categorised as a consequence class 2b (Upper Risk Group) as it is a test which aim is to reproduce the behaviour of high occupancy and taller buildings. Subsequently the building was also designed following the simplified method of tying forces and elements (horizontal and vertical ties) [15]. A discussion of the origins and validity of the simplified tie method can be found in [7]. All the structural members complied with the tying force 
106 requirements except for column P5 for which the reinforcement was increased compared to the

107 other columns as shown in Fig. 3.

108 Figs. 2-3 summarize the final design of the RC building structure. For flat-slabs, a two-layer

109 reinforcement grid (top and bottom) was considered with $12 \mathrm{~mm}$ diameter bars spaced at $20 \mathrm{~cm}$.

110 Extra reinforcement was adopted in the top layer, as shown in Fig. 2. Nominal concrete cover was

$11130 \mathrm{~mm}$. The flat-slabs also had $30 \mathrm{~cm}$ wide edge RC beams (see Fig. 2) of the same thickness as

112 the slabs and introduced as a general adopted practice to withstand the edge moments and torsion.

113 Fig. 3 shows the slab punching reinforcement in the position of different columns, plus the column

114 reinforcement which was all designed using Eurocode 2 for the design loads give above. The

115 target characteristic compressive strength of the concrete (cylinder strength) for the entire

116 structure was $30 \mathrm{MPa}\left(\mathrm{f}_{\mathrm{ck}}=30 \mathrm{MPa}\right)$ and control specimens were taken at the time of testing for

117 the different structural elements. The reinforcement characteristic yield strength was $500 \mathrm{MPa}$

$118 \quad\left(\mathrm{f}_{\mathrm{yk}}=500 \mathrm{MPa}\right)$. 


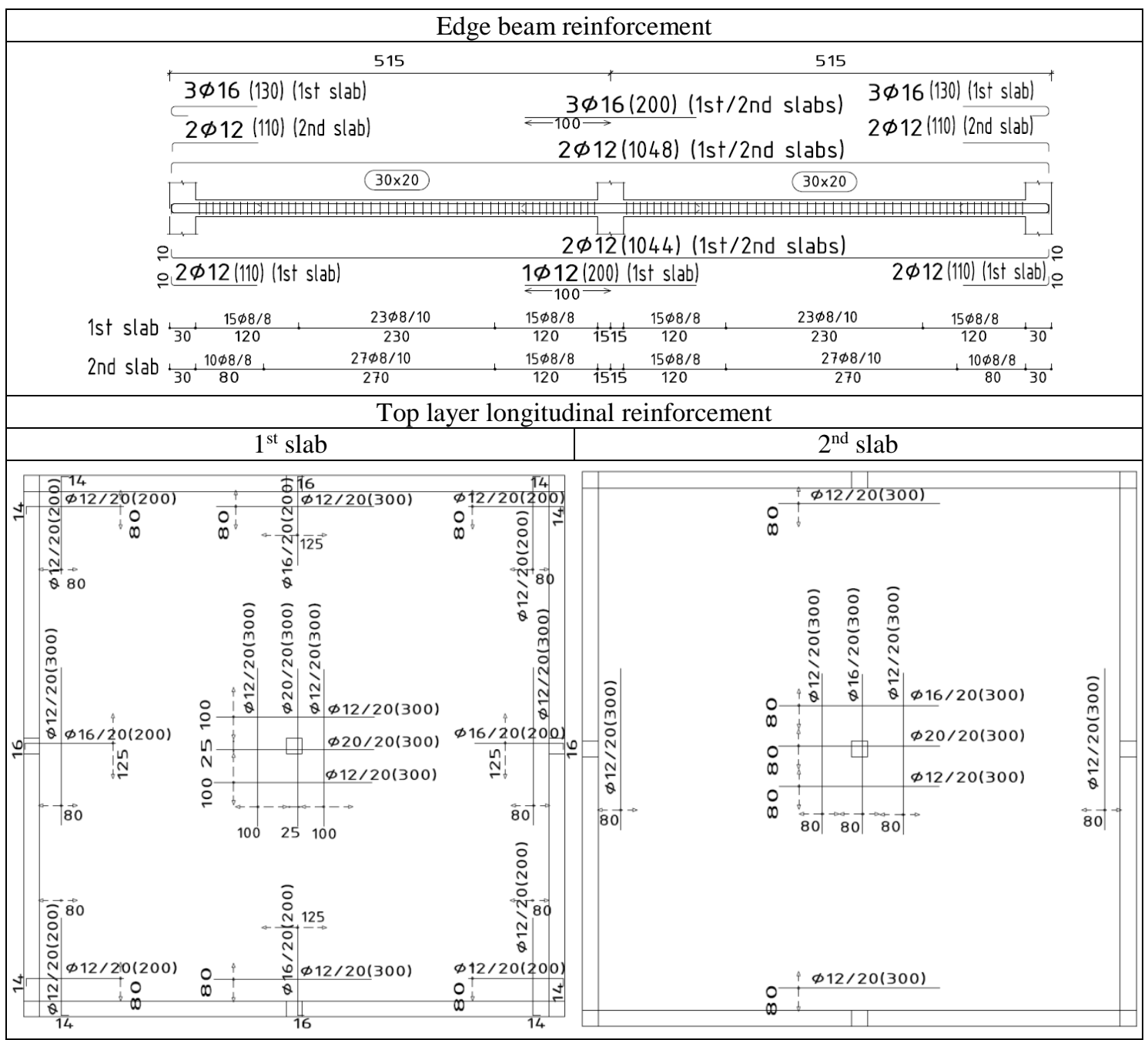

119

Fig. 2. Longitudinal reinforcement for top layer edge beams and slabs. Bar diameters in mm. Distances in $\mathrm{cm}$ and lengths are specified between brackets. 


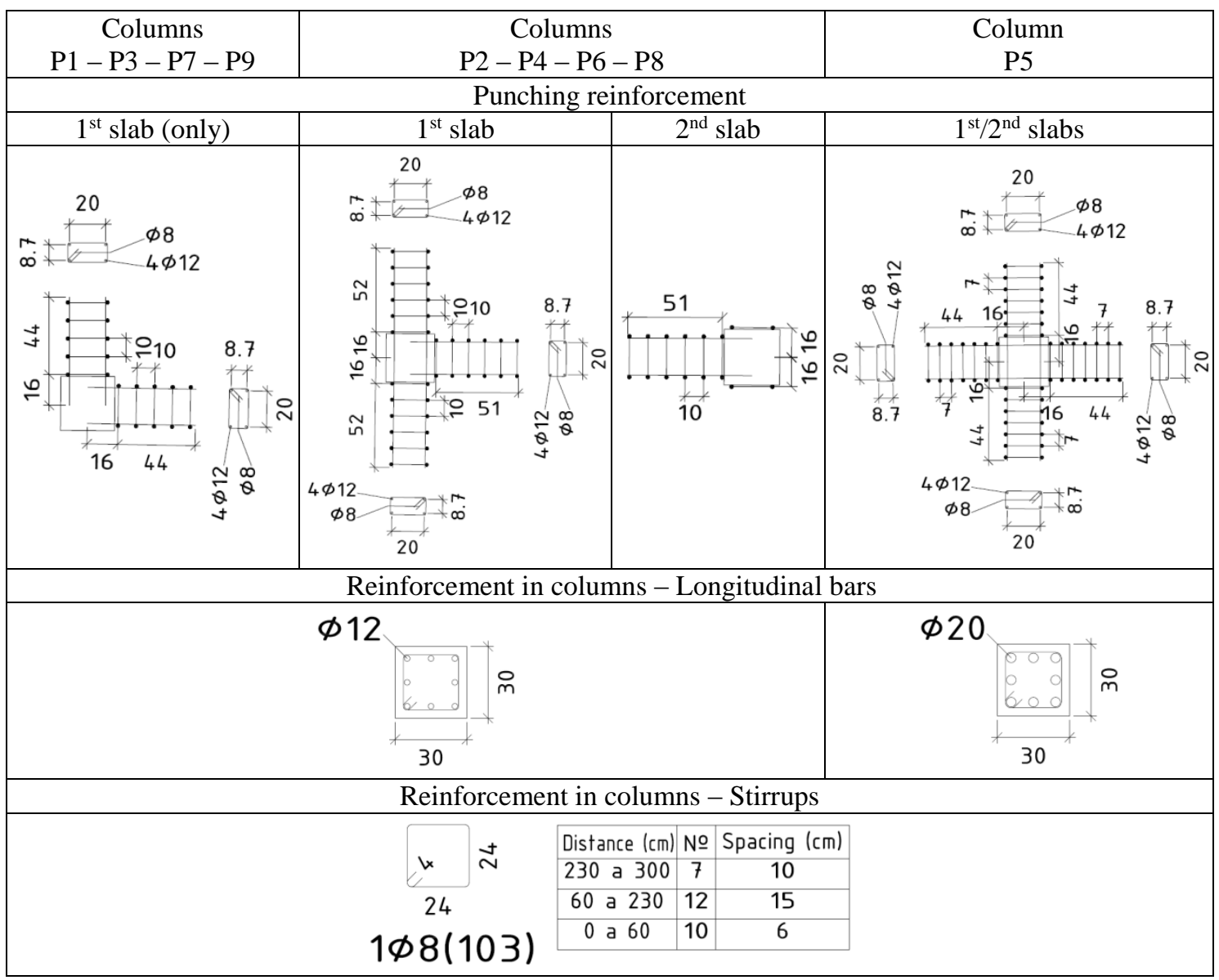

122

Fig. 3. Punching reinforcement and reinforcement in columns. Bar diameters in mm. Distances in cm.

The building was constructed in 51 days and the test was carried out 34 days after the concrete was placed in the $2^{\text {nd }}$ slab. The mechanical properties of the concrete were measured for different concrete ages and elements (columns and slabs). The control specimens provided information on: (i) compressive strength (4 cylinders per age and structural member, $30 \mathrm{~cm}$ height and $15 \mathrm{~cm}$ diameter, following EN 12390-3); (ii) elastic modulus (3 cylinders per age and structural member, $30 \mathrm{~cm}$ height and $15 \mathrm{~cm}$ diameter, following EN 12390-13); (iii) tensile strength (3 Brazilian cylinder tests per age and structural member, $30 \mathrm{~cm}$ height and $15 \mathrm{~cm}$ diameter, following EN 12390-6 and 3 flexural prismatic tests per age and structural member, $60 \mathrm{~cm}$ by $15 \mathrm{~cm}$ by $15 \mathrm{~cm}$, following EN 12390-5). The tensile strength was only tested for slabs. Table 1 shows the mean values obtained. 
134 Table 1. Mechanical properties of concrete for columns and slabs.

\begin{tabular}{|c|c|c|c|c|}
\hline Mechanical property & Element & Age [days] & Results [MPa] & Test \\
\hline \multirow{4}{*}{ Compressive Strength } & Ground floor columns & 57 & 32.2 & \\
\hline & $1^{\text {st }}$ slab & 43 & 30.5 & \\
\hline & $1^{\text {st }}$ floor columns & 42 & 33.2 & \\
\hline & $2^{\text {nd }}$ slab & 34 & 31.1 & \\
\hline \multirow{4}{*}{ Elastic Modulus } & Ground floor columns & 57 & 29275 & \\
\hline & $1^{\text {st }}$ slab & 43 & 28810 & \\
\hline & $1^{\text {st }}$ floor columns & 42 & 29403 & \\
\hline & $2^{\text {nd }}$ slab & 34 & 33119 & \\
\hline \multirow{4}{*}{ Tensile Strength } & Ground floor columns & 57 & --- & \\
\hline & $1^{\text {st }}$ slab & 43 & 2.44 & \\
\hline & $1^{\text {st }}$ floor columns & 42 & --- & \\
\hline & $2^{\text {nd }}$ slab & 34 & 1.83 & \\
\hline \multirow{4}{*}{ Flexural Strength } & Ground floor columns & 57 & --- & \\
\hline & $1^{\text {st }}$ slab & 43 & 4.52 & \\
\hline & $1^{\text {st }}$ floor columns & 42 & --- & \\
\hline & $2^{\text {nd }}$ slab & 34 & 4.08 & \\
\hline
\end{tabular}

135

\section{3. Description of testing and monitoring}

\section{3.1. Failure scenario and gravity loads}

138 The local failure scenario consisted of the sudden removal of corner-column P3 (see Fig. 1).

139 Corner columns are usually those most exposed and thus vulnerable to extreme events which

140 could initiate progressive collapse. This scenario was thus deliberately chosen to study the

141 capacity of a full-scale structure to seek ALPs and assessing the dynamic response.

142 As required in Eurocode [46], the total load considered for a combination of actions for

143 accidental situations for a high occupancy building category $\mathrm{C}$ was $1.0 \cdot \mathrm{DL}+0.7 \cdot \mathrm{LL}$, where $\mathrm{DL}$ is

144 the dead load including that of the outside walls and LL is the live load. The GSA Guidelines [13]

145 consider for accidental situations a total load of $1.2 \cdot \mathrm{DL}+0.5 \cdot \mathrm{LL}$. In this work it was finally

146 adopted a superimposed (additional) uniformly distributed load (ignoring the loads on the outside

147 walls) equal to $4.9 \mathrm{kN} / \mathrm{m}^{2}$, which is the value required following the GSA Guidelines [13] which

148 is slightly higher than the load required by Eurocode $\left(4.1 \mathrm{kN} / \mathrm{m}^{2}\right)$ [46]. This load was reproduced

149 by means of uniformly distributed concrete blocks arranged in the bays with the column removal 
150 (the remaining bays had no superimposed loads). The blocks used for the superimposed load were

151 heavier than initially intended leading to a final load of $5.3 \mathrm{kN} / \mathrm{m}^{2}$. On the first floor, the weight

152 of a hypothetical outside wall was also considered by adding blocks at the edges; this was roughly

153 equivalent to a line load of $0.56 \mathrm{kN} / \mathrm{m}$. Fig. 4 shows a photo of the finished building ready for

154 testing, with two views of the superimposed loads placed on each floor.
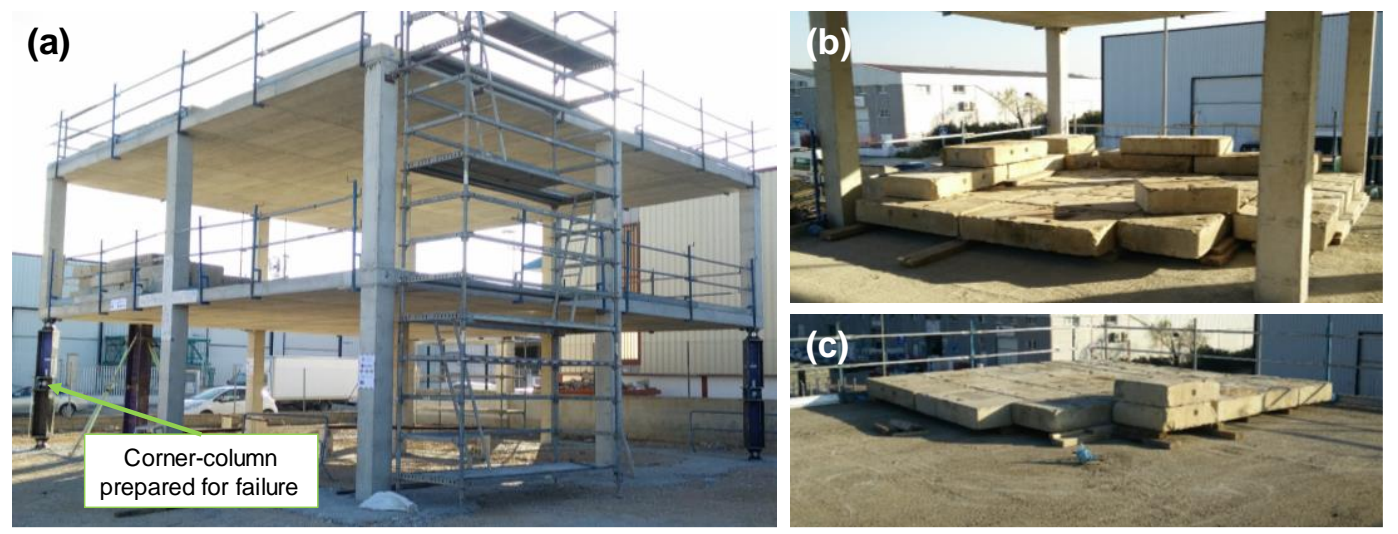

Fig. 4. Details of the building (a) and the superimposed loads for the accidental situation on Floors 1 (b) and 2 (c).

\subsection{Design of the corner-column for the failure scenario}

The sudden removal of column P3 on the first floor was achieved effectively using a steel girder (HE-300B) fitted with three unidirectional hinges (see Fig. 5) which was specially designed

161 for this purpose. The intermediate hinge had a provisional block that allowed the column to

162 withstand the loads applied prior to the column removal. This hinge block allowed the movement

163 in a single direction and included a fitted U-shaped steel girder (UPN-240) with a pin restrain to

164 keep the girder in place during the building construction.

The upper hinge was anchored to the slab and upper column to mimic a conventional concrete column, (i.e. the threaded bars used remained vertical prior to placing of the concrete of the slab

167 and second-floor column). The lower hinge was fixed to the foundations by means of threaded

168 bars and an anchor plate. All three hinges were turned $45^{\circ}$ to allow the corner of the building to

169 move downwards freely. Details of the column design can be seen in Fig. 5, together with a view

170 of the completed column, details of the central hinge block and the connections between the upper

171 and lower parts. 
173 the intermediate hinge) which was followed by a slight destabilisation of the column using a

174 forklift. Fig. 6 shows the moment just before the column was destabilised. For safety reasons an

175 additional column (unattached to the building structure as shown in Fig. 6) was placed next to the removed column to prevent the total collapse of the structure.

177 The steel hinged column device adopted in the test was chosen over other alternatives such

178 as explosives or impact loads, which can be expensive and involve a certain amount of risk. These

179 alternative approaches can also generate vibrations and induced strains that can affect the results

180 obtained in the early stages of the tests. The column was also designed to be re-usable, i.e. after

181 the test it could be pushed back into place to return the slab to its original position and could be

182 used in subsequent tests in other parts of the building.

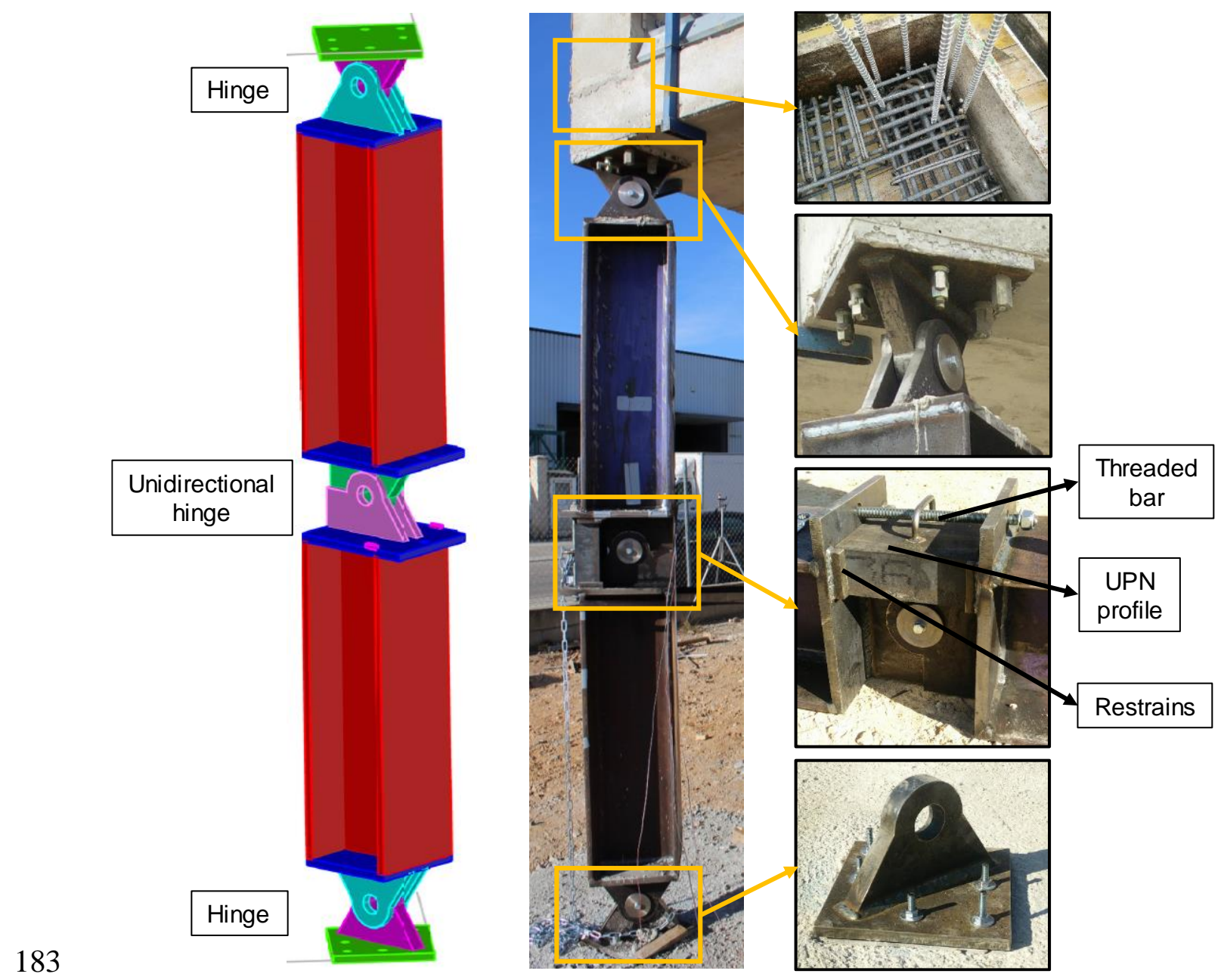

Fig. 5. Details of column design and installation. 

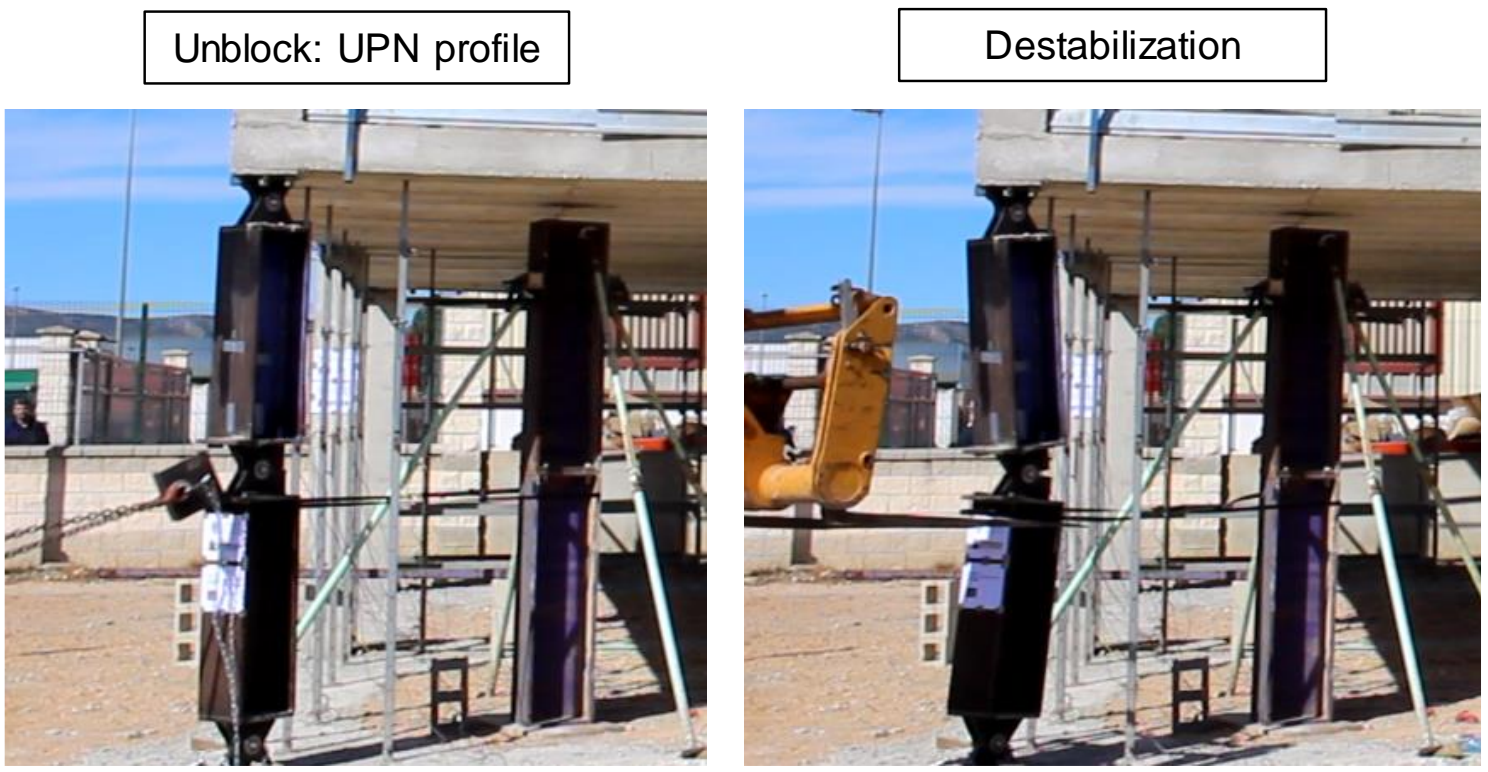

Fig. 6. Reproduction of the sudden failure of the column.

\section{3.3. Monitoring}

An extensive monitoring plan was designed with a total of 38 strain gauges, 38 LVDTs and

2 accelerometers. Four strain gauges were installed on the reinforcement bars on each of the firstfloor (P1, P2, P3, P5, P6 y P7) and second-floor columns (P2, P3, P5 y P6), while three were fitted to the web and flanges of the HE-300B girder in the steel column (P3) (see Fig.7). These were labelled following the pattern SG_Column-XY, where X indicates the floor (from 1 to 2) and $\mathrm{Y}$ indicates the number and position of the strain gauge (from 1 to 4 ).

Seventeen of the 20 LVDTs placed horizontally on the top and bottom slab surface were used to measure bending in the slab-column joint (see Fig.7); these were labelled following the pattern LVDT-Column-XYZ, where $\mathrm{X}$ indicates the floor, $\mathrm{Y}$ indicates the number and position of the

197 LVDTs, and Z adopts letters $\mathrm{H}$ or V which means horizontal or vertical, respectively. Three horizontal LVDTs measured the building drift towards the failed column on Floors 1 and 2 (see Fig. 8). 


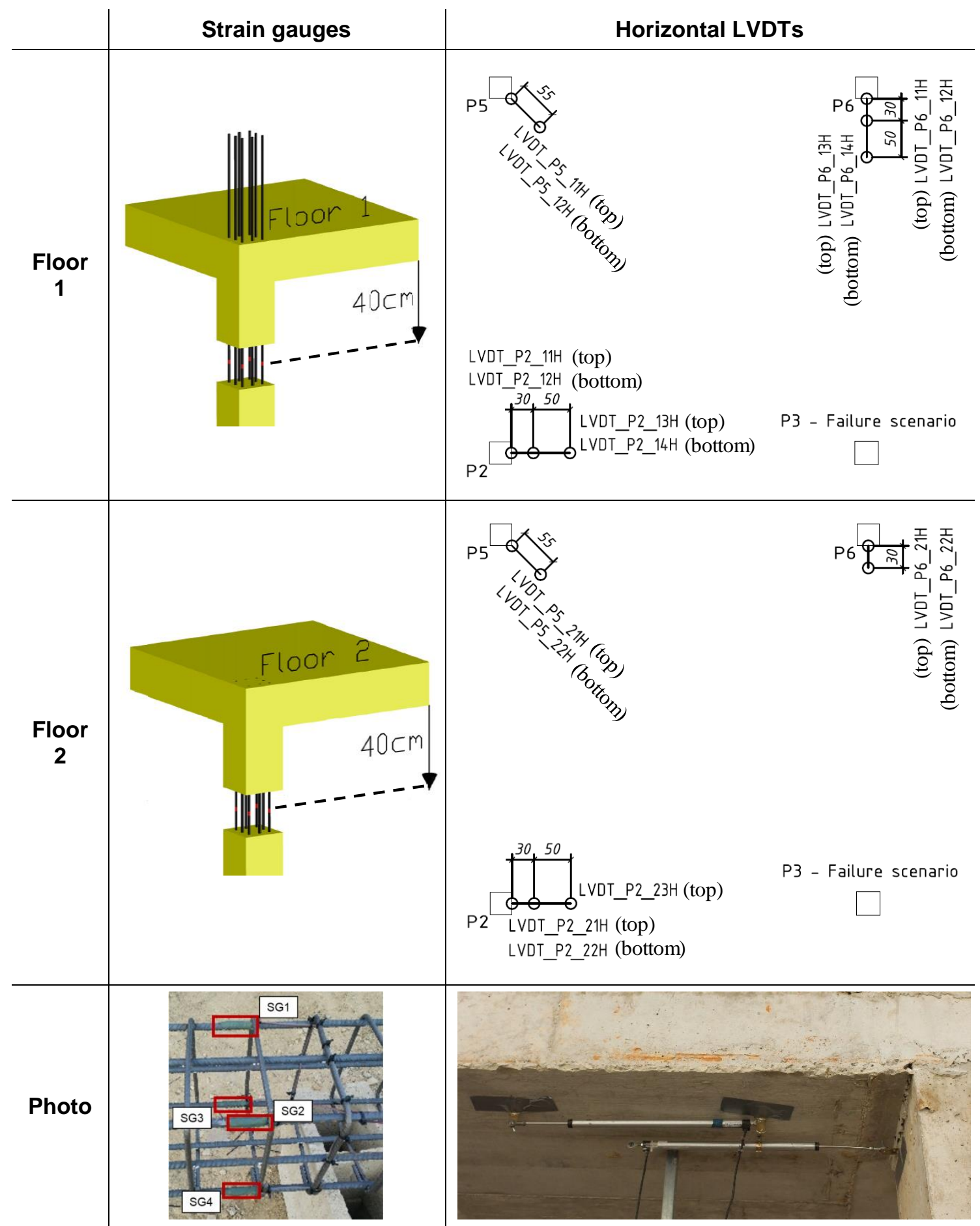

Fig. 7. Position of strain gauges and horizontal LVDTs.

201 Eighteen LVDTs measured vertical displacement at different points in the structure. Eleven

202 were used to measure slab deformation at a distance of three times the effective slab depth from

203 the columns face $(47 \mathrm{~cm})$. Two vertical LVDTs measured vertical structural displacement at 50

$204 \mathrm{~cm}$ from the failed column (P3) and two others the deformation of the P2-P3 alignment (1/3 and 
206 vertical LVDTs (green cylinders in Fig.8) recorded the time-history settlement of the foundations 207 of columns P2, P5 and P6.

208 The vertical accelerations generated during the test in the upper section of the failed column and horizontal accelerations over P1 towards P3 were measured by two fibre optic accelerometers 210 (red cylinders in Fig.8).

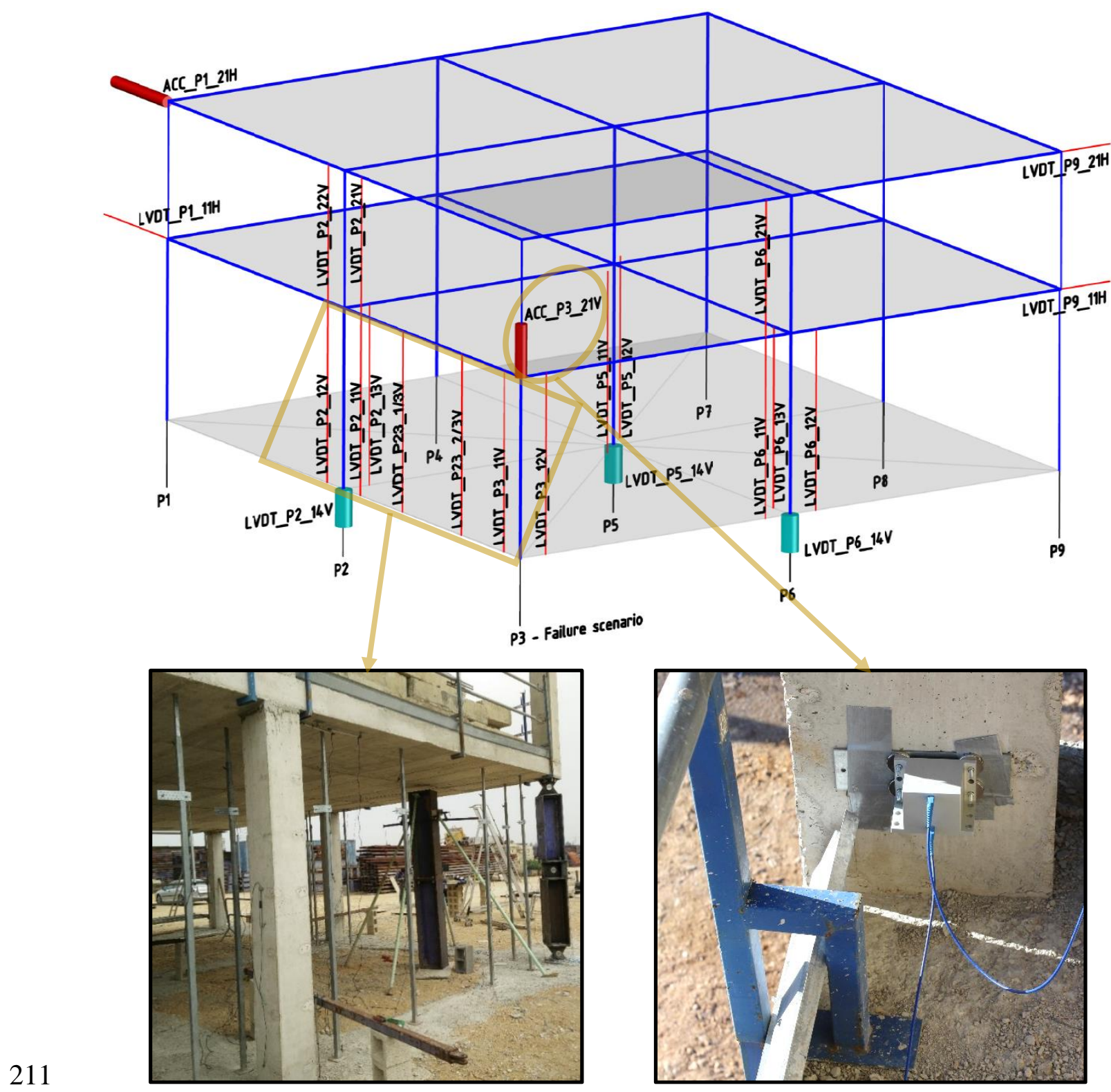

Fig. 8. Position of vertical LVDTs and accelerometers. 
A high-capacity 78-channel data acquisition system was used to monitor the deformation and

214 displacement sensors at a rate of 200 measurements per second $(200 \mathrm{~Hz}$ frequency). The fibre

215 optic sensors used an optical sensing interrogator operated at the same frequency.

216

217 4. Time-history results and final state of the structure

\section{4.1. Vertical displacements}

Fig. 9 shows the time-history of the vertical displacement of one of two LVDTs close to the

220 failed column P3. Both sensors (P3_11V and P3_12V) showed similar values, with a maximum

221 descent of $48.1 \mathrm{~mm}$ and stabilised at $42.8 \mathrm{~mm}$ two seconds after the sudden column removal.

222

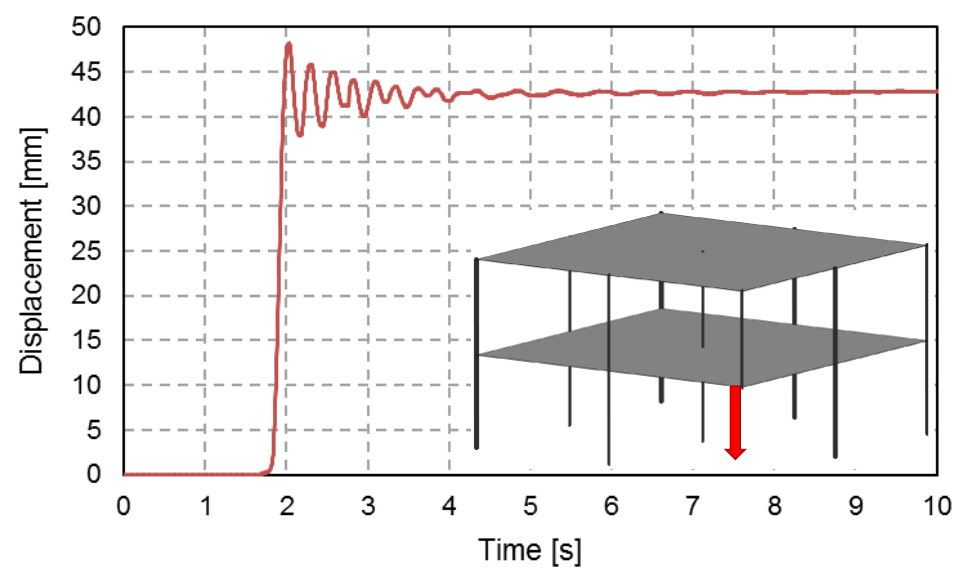

Fig. 9. Vertical displacement in the position of the failed column.

The deformation profile between P2 and P3 was recorded by four LVDTs (P2_11V, P23_1/3V, P23_2/3V and P3_11V, see positions in Fig. 8). Fig. 10 gives the results obtained before, during and after the removal of $\mathrm{P} 3$. The positions of the sensors can be seen, together with a time-history graph of vertical displacements with time. Peak displacements and residual displacements are also given. The ratio between peak and residual values ranges from 1.12 (P3_11V) to $1.16\left(\mathrm{P} 2 \_11 \mathrm{~V}\right)$. 

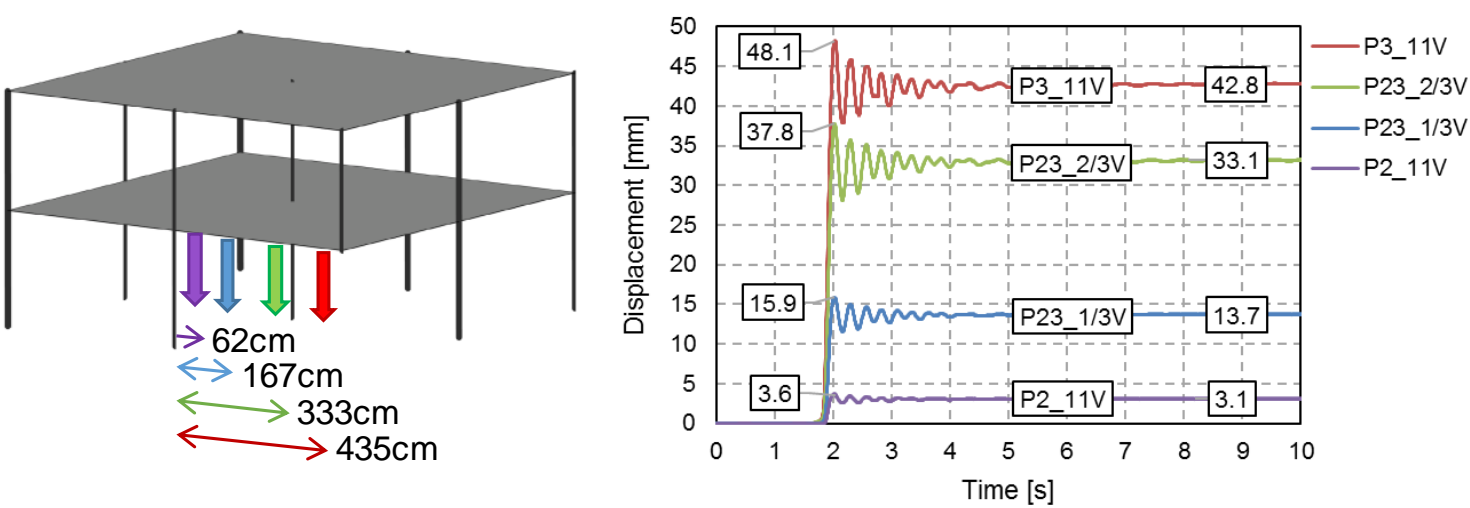

Fig. 10. Vertical displacements between columns P2 and P3.

\section{4.2. Horizontal displacements}

233 Horizontal displacement was measured by the LVDTs in order to investigate: a) bending

234 deformations (flexural and Vierendeel actions) and in-plane deformations (membrane action) using sensors placed on column-slab joints; and b) drift of the structure after the sudden removal of column P3 using sensors referenced to a fixed point outside the structure.

Fig. 11 shows the relative horizontal displacement time-history results for the seven LVDTs

238 on column-slab joints around columns P2 and P6 on the first and second floors (P2_11H, P2_12H,

239 P2_22H, P6_11H, P6_12H, P6_21H and P6_22H, see positions in Fig. 7). The data from sensor

240 P2 $21 \mathrm{H}$ is not shown as the sensor was faulty during the test. The results show that the upper face

241 of the slab is in tension while the lower is under compression, with tensile deformation higher

242 than compression deformation due to localised slab cracking. Slightly asymmetric behaviour can 243 also be seen in the first-floor structure, where the sensors close to P6 recorded larger 244 displacements than those around P2, although those on the second floor all gave similar values. 
Floor 1

P2
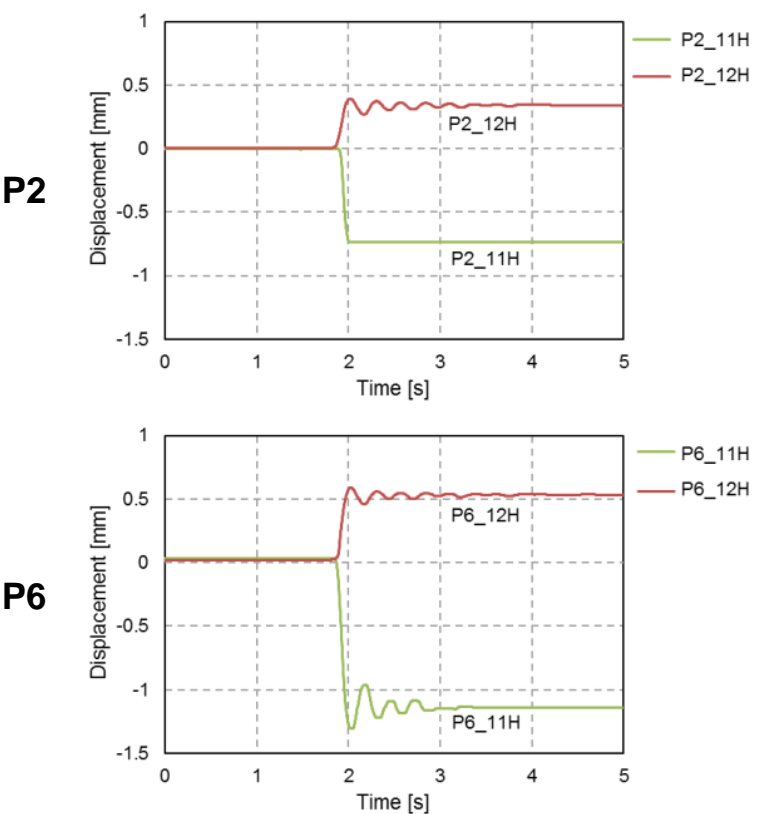

Floor 2
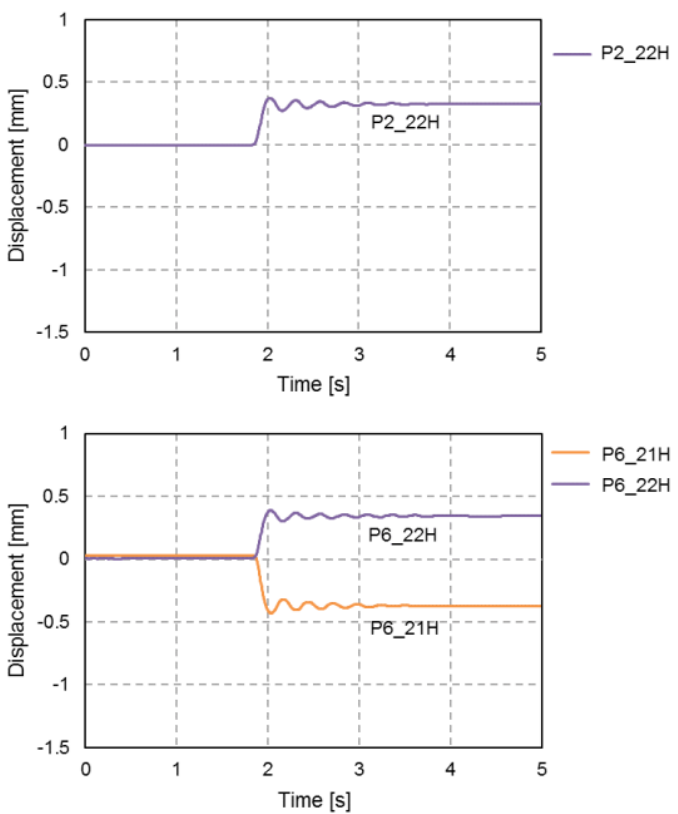

Fig. 11. Horizontal displacements on slabs near columns P2 and P6 on first and second floors. Positive values represent compression displacements.

Fig. 12 shows the time-history of the drift of the building $\left(\mathrm{P} 1 \_11 \mathrm{H}, \mathrm{P} 9 \_11 \mathrm{H}\right.$ and P9_21H, see

positions in Fig. 8). P1 and P9 gave similar results on the first floor, with a residual difference

value of approximately $0.4 \mathrm{~mm}$, and slightly different peak values, with P9 showing the higher

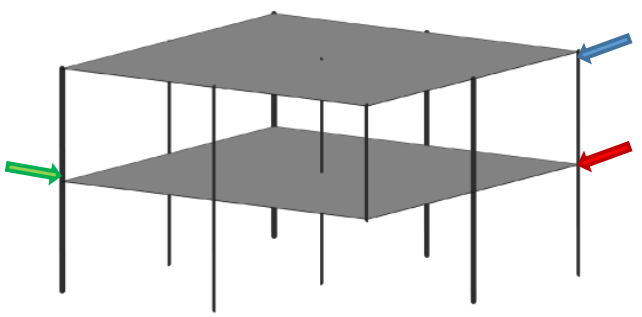

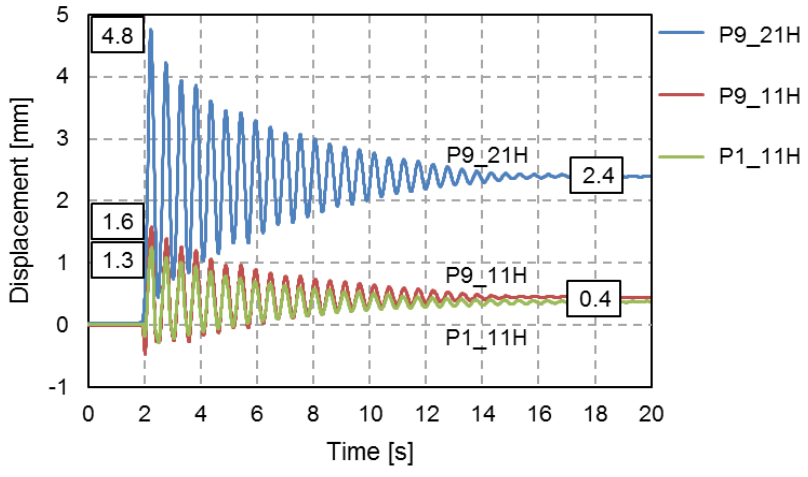

Fig. 12. Drift of the building after the sudden removal of the corner column. Positive values represent displacements towards $\mathbf{P 3}$, as indicated by the arrows. 


\subsection{Strain in columns}

P3 was monitored by 3 strain gauges to measure: a) column load before the sudden removal 260 and b) column unloading time. Fig. 13a gives the mean values of P3, with an unloading time of 261 approximately $0.1 \mathrm{~s}$ and $44.7 \mu \varepsilon$ of elongation $(140 \mathrm{kN})$.

The columns nearest P3 (P2, P5 and P6) were also monitored. Fig. 13b shows the mean values of the four strain gauges fitted to these columns on the first floor (represented with the following codes P2_1, P5_1 and P6_1) to measure the increased axial force on these columns. It can be seen that P2 and P6 absorb high compression forces (i.e. shortening strains), while the load in P5 remains fairly constant with a small unloading. Residual values of the load increments are 37.4 $\mu \varepsilon(104 \mathrm{kN})$ and $48.5 \mu \varepsilon(135 \mathrm{kN})$ in $\mathrm{P} 6$ and $\mathrm{P} 2$ respectively, showing increased compression values close to the unloading values of P3 $(140 \mathrm{kN})$. As explained in Section 5, the higher load in the neighbouring P2 and P6 columns can be explained by the unloading of other columns due to the global eccentricity of the load in the building (in the direction P5-P3) after column removal. P2 (48.5 $\mu \varepsilon)$ showed higher residual compression deformation increments than P6 (37.4 $\mu \varepsilon)$,

272 but the same did not happen with the peak values, $(67.0 \mu \varepsilon$ and $64.1 \mu \varepsilon$ for P2 and P6, 273 respectively). This can be explained by the more severe cracking and deformation of the zone 274 close to P6 than around P2 (see Fig. 11 and Section 5), reducing the stiffness in this zone on reaching maximum load and thus re-distributing part of the load to stiffer regions. The ratio between peak and residual loads, which depends largely on load distribution during the dynamic action, had values ranging from 1.38 to 1.71 in $\mathrm{P} 2$ and $\mathrm{P} 6$ respectively.

(a)

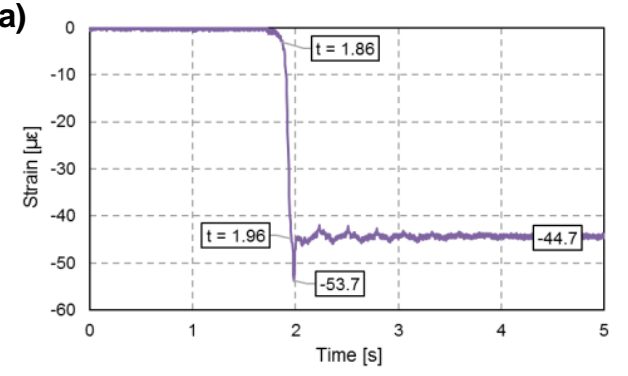

(b)

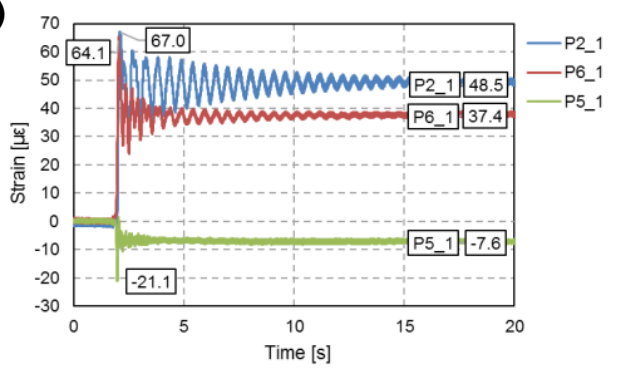

Fig. 13. Mean first-floor strain gauge value for columns: (a) P3, and (b) P2, P6 and P5. Positive values indicate shortening and negative indicates decompression. 
Besides higher axial forces, the sudden column removal also caused significant variations in

282 the column bending moments including P2 and P6. These bending moments were assessed by

283 analysing the deformation data from the four strain gauges $40 \mathrm{~cm}$ below the slab on the upper

284 section of the columns. These results confirm the contribution of flexural and Vierendeel action

285 similar to that reported for frame buildings [50,51].

286 Fig. 14 shows the deformation recorded by the strain gauges in P6 at the first and second

287 floors (Figs. 14a and b). The two strain gauges on the side of P6 closest to P3 give compression

288 deformation increments (shortening), while the other two are in tension (elongation). These values

289 indicate the presence of large bending moments leading to an overall rotation of the slab-column

290 joint towards P3. These values are much higher than those recorded for axial force deformation

291 (see Fig.13b), reaching a peak of $283.7 \mu \varepsilon$, denoting the high flexural deformation of the slab-

292 column joint.

(a)

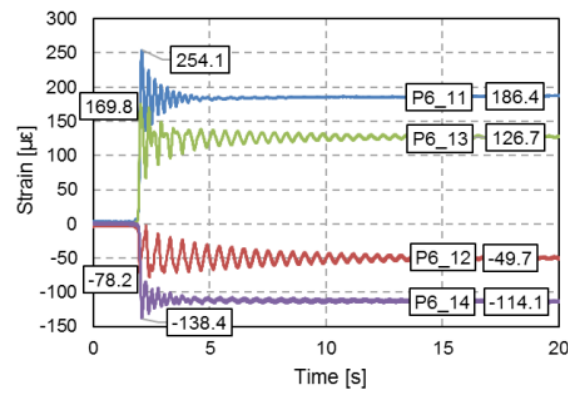

(b)

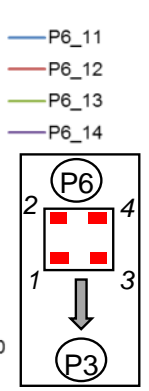

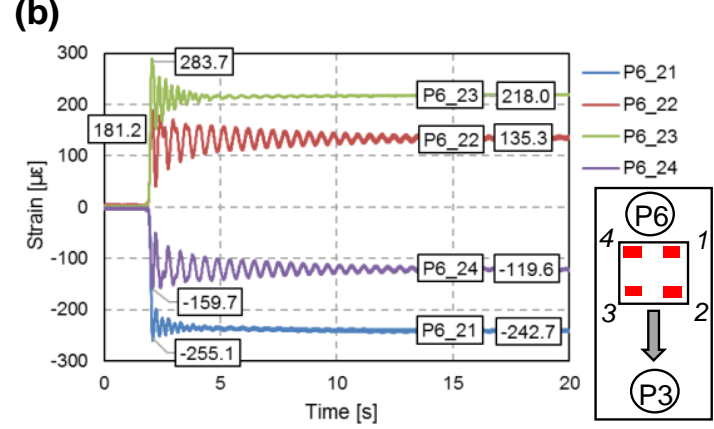

293

Fig. 14. Strain measures in P6 on the first (a) and second (b) floors. Positive values represent shortening.

\subsection{Acceleration}

The acceleration measured above the removed column is shown in Fig. 15. The vertical acceleration is close to free fall with a peak value of $1.08 \mathrm{~g}$ followed by the high frequency oscillation phase. These results demonstrate that the sudden removal of the corner column was successfully reproduced in the test. The results also show the dynamic response of the structure, with a clear recoil, reaching a deceleration of up to $0.65 \mathrm{~g}$. Fig $15 \mathrm{~b}$ shows the horizontal 
(a)

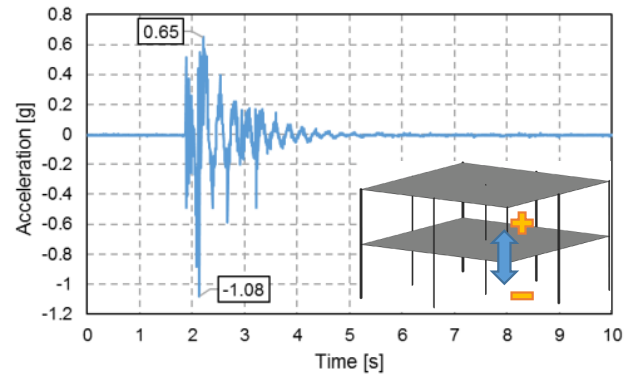

(b)

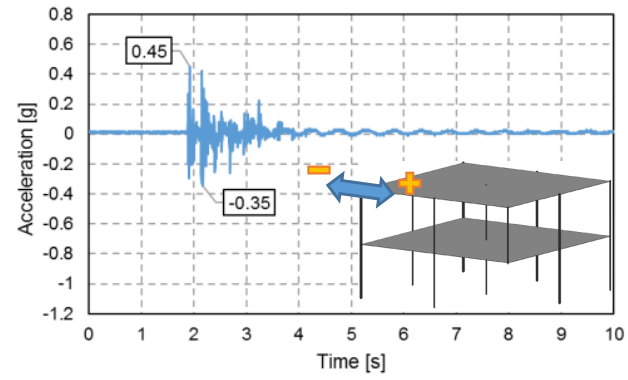

Fig. 15. Vertical (a) and horizontal (b) acceleration in column P3 ( ( $^{\text {st }}$ floor $)$ and column P1 ( $2^{\text {nd }}$ floor), respectively.

\subsection{Residual damage after the test}

There was no extensive cracking in the structure before and after removing the column; only the upper slab surface around P2 and P6 were affected, as confirmed by the results given in Fig.11. Flexural cracks in the slab were visible near the column-slab connection as shown in Fig. 16. At

311 the end of the test, for safety reasons, P3 was pulled back into its original position by a cable until

312 the central hinge re-blocked; flexural cracks closed consequently.
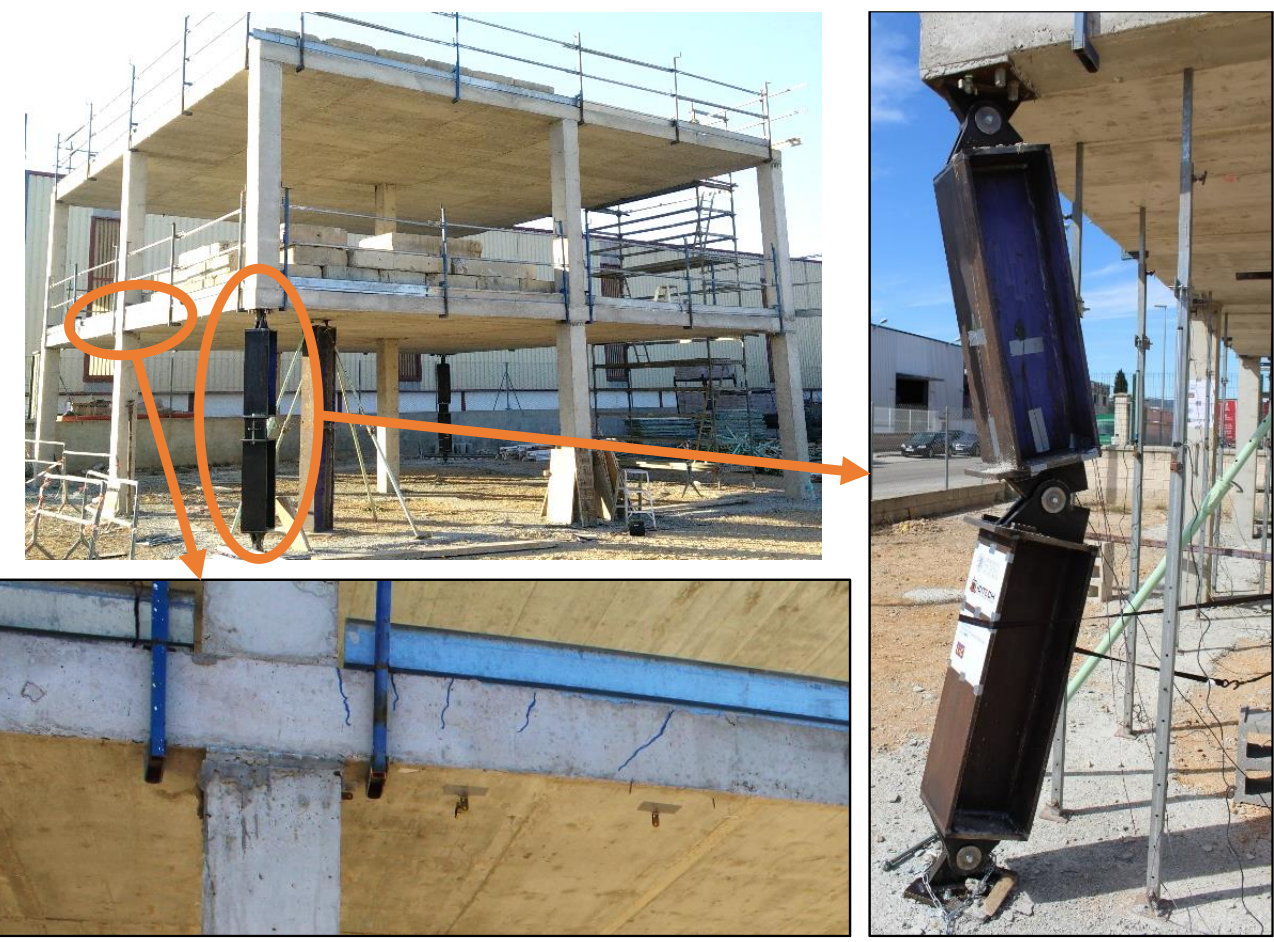

314 Fig. 16. Final state of the removed column and detail of cracking on P2 slab-column joint ( $1^{\text {st }}$ floor). 


\section{5. Analysis and discussion of results}

316 This section deals with: a) slab flexural deformation around the neighbouring columns (P2,

317 P5 and P6); b) the re-distribution of the load originally carried by P3; c) the overall behaviour of

318 the structure and the main ALPs after the sudden removal of the corner column; and d) a

319 description of the linear static numerical analysis carried out to evaluate the dynamic

320 amplification factors (DAF) defined in the DoD guidelines [14].

\section{$321 \quad$ 5.1. Deformability of slabs around adjacent columns}

322 Fig. 17 gives the residual vertical displacements around columns P2, P5 and P6 and represents

323 the situation before (black spheres) and after (red spheres) the column removal. Each sphere is

324 separated from the column face by a distance of three times the effective slab depth $(47 \mathrm{~cm})$. The

325 position at which the measurements were taken is given in brackets, with reference to Fig. 8 , next

326 to the vertical displacement, in addition to the column number and floor. The results clearly show

327 that the nodes turned towards the position of P3, with a pronounced drop at the closest point to it

328 and a slight rise at the opposite point. This is a typical situation of a column-slab connection

329 subjected to moment transfer.

330 The data supplied here will be subjected to a more in-depth analysis using simplified corner

331 column failure methods in order to determine the dynamic punching demand and resistance.

332 Flexural rotations vary significantly close to the column whereas further from the column they

333 become fairly constant. The constant value of the slab rotation, which can be obtained from the

334 measured data, is the one of real interest for assessing punching resistance. In any case, the test

335 shows that punching shear was not critical for the accidental load combination investigated. 
(a)

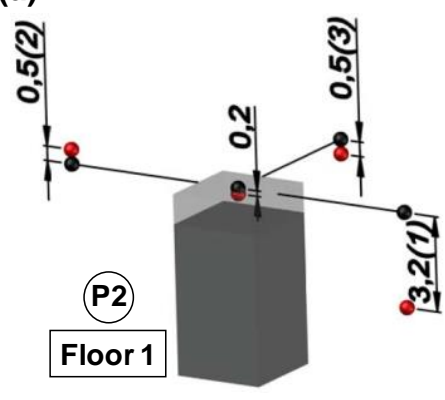

(d)

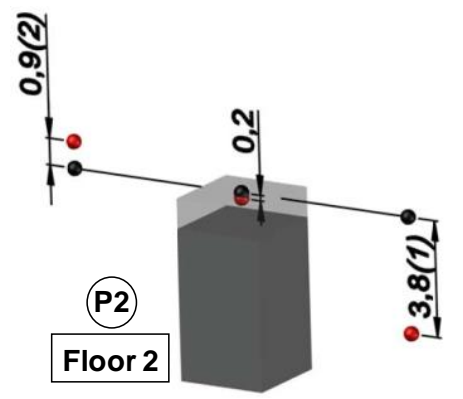

(b)

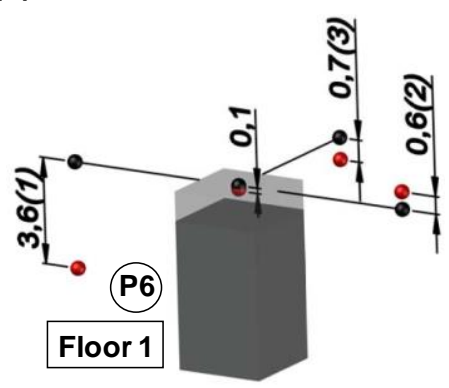

(e) (c)

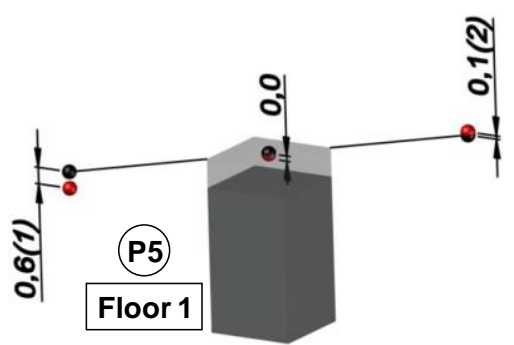

Fig. 17. Residual displacements after the sudden removal of column P3 around columns P2 (a and

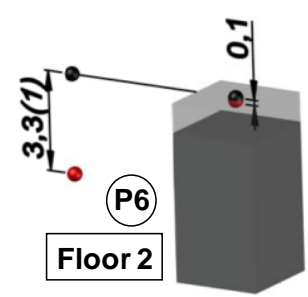
d), P6 (b and e) and P5 (c). Units in mm. Scale factor of 100 for vertical displacements.

\subsection{Analysis of the load redistribution after column removal}

The results obtained show that the sudden unloading of the corner-column (P3, initially

341 carrying $140 \mathrm{kN}$ ) resulted in a large increase of the residual axial load in the neighbouring columns. The value of the load increase ( $135 \mathrm{kN}$ and $104 \mathrm{kN}$ for P2 and P6 respectively) is similar to the load on the corner-column before it was removed. This is different to column removal scenarios for internal columns for example where only a fraction of the load carried by the column is transferred to the neighbouring columns after column removal.

In this test it is shown that the load in P3 is transferred to P2 and P6 with a significant 347 additional axial load and moment transfer due to the unloading of other columns. This response 348 is due to the global eccentricity of the load and the asymmetry of the building after column removal. To further illustrate this behaviour, Table 2 gives the mean deformation and residual axial force increments (calculated from the strain increments measured by the 4 strain gauges on each column) of P3, P2, P6, P1, P5 and P7. All the first-floor columns except P2 and P6 are shown to experience a reduction of the axial loads. 
If $\mathrm{P} 9$ is considered to reduce its load by a similar amount to P1, and if the reduced load on P4

354 and $\mathrm{P} 8$ is between the reduction on $\mathrm{P} 1$ and $\mathrm{P} 7$, the total axial forces (or vertical reactions) of the 355 structure are in equilibrium. It can also be seen that the reduced load on P1 is even slightly higher 356 than the reduction of P5 (closer to P3), which, together with the large load increases on P2 and 357 P6, underlines the importance of the outside frames working with the flexural and Vierendeel beam actions. These global effects and the contribution of the different floors to the search for

359 ALPs could not have been considered had the test been made on a sub-assemby.

Table 2. Analysis of the load redistribution after the sudden removal of column P3. Shortening strain increments are positive.

\begin{tabular}{ccc} 
Column & Residual mean strain $[\mu \varepsilon]$ & Axial force increment $[\mathrm{kN}]$ \\
\hline P3 (removed) & -44.7 & -140 \\
P2 & 48.5 & 135 \\
P6 & 37.4 & 104 \\
P1 & -8.9 & -25 \\
P5 & -7.6 & -21 \\
P7 & -3.6 & -10 \\
\hline
\end{tabular}

362

\subsection{Analysis of ALPs of the structure}

The main ALPs were analysed for the corner-column failure scenario tested. After this type of event there are different possible ALPs [1]: (i) flexural or slabs acting as cantilevers, (ii) Vierendeel beam, (iii) tensile membrane action, (iv) compressive membrane action and (v) others such as the possible contribution of partitions or secondary trusses. The compressive membrane effect (iv) and contribution of partitions (v), are not applicable to the case under study since the former is not possible in corner-column failure scenarios and partitions were not considered in

370 the study. Flexural action was obviously present in the test carried out, since the corner bay 371 remained partially functioning as a cantilever (see Figs. 11-16). The Vierendeel beam mechanism was also activated. As already mentioned, Vierendeel behaviour can be proved by the deformed shape of the structure (columns experienced severe flexural deformations and slabs had a doublecurvature deformation as shown in Fig. 18). Fig. 18a shows the vertical deformed shape of the

375 first-floor slab between P2 and P3. The results show that deformation is not only due to flexural 376 or cantilever action, but that the Vierendeel beam effect is also significantly present. 
Fig. $18 \mathrm{~b}$ shows the horizontal deformation of $\mathrm{P} 9$ as representative of the drift of the structure.

378 The deformation is not uniform, but is approximately five times greater on the second than the

379 first floor, and also indicates the existence of the Vierendeel beam mechanism, which reduced the

380 horizontal deformation on the first floor. It should be noted that this mechanism also requires the

381 bending capacity of the slab-column joints which is limited due to punching and moment transfer.

(a)

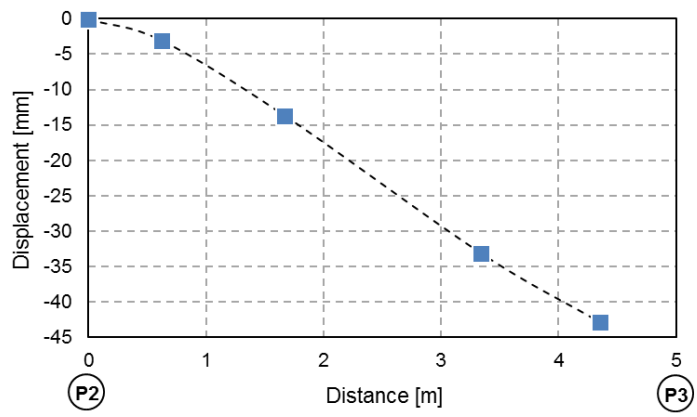

(b)

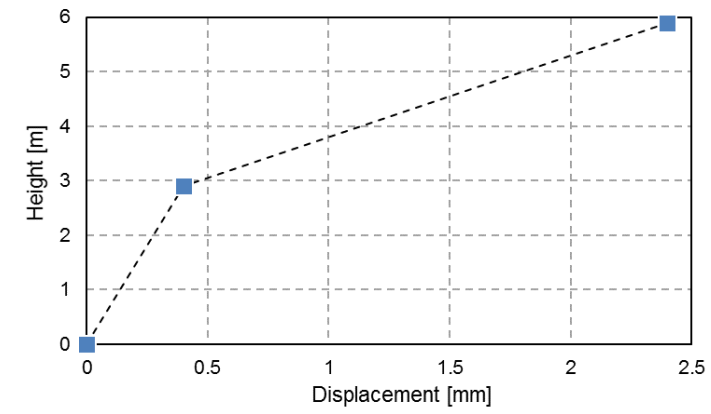

Fig. 18. Vertical residual displacement of the first floor between columns P2 and P3 (a) and horizontal residual displacement of column P9 (b).

Membrane action (compressive and tensile) was not activated in the test. Compressive membrane action due to restraint slab dilatancy from cracking was not possible, other than locally at slab-column joints, due to the lack of in-plane restraint at the edges of the bay of the column removal. This situation is different for internal column removal where in-plane restraint takes place. Tensile membrane action which may be present in corner-column failures, it is often considered as an extra reserve that comes into play after the activation of flexural and Vierendeel

391 beam mechanisms [37]. The deformation of the slab after column removal was small (48 mm near P3); as an order of magnitude this value is near the prescribed limit of span L/250 imposed by Eurocode 2 [48] to avoid functionality issues (general utility and appearance). This value is considerably lower than the usual range where tensile membrane action is activated; snap-through just before the activation of tensile membrane action occurs at vertical deflections of the order of

396 the thickness of the slab [52-54]. It can be concluded that the main ALPs in the test were flexural 397 and Vierendeel actions. 


\subsection{Evaluation of Dynamic Amplification Factors (DAFs)}

400 The international recommendations for the design of robust buildings (e.g. US Department of

401 Defence (DoD) [14]) allow linear static analysis as a simplified calculation method as part of the 402 Alternative Load Path method, without considering more complex aspects such as mechanical 403 non-linearities and dynamic (inertial) effects. However, the calculations must include dynamic 404 load amplification factors (DAFs) to cover any effects not taken into account; these are embedded 405 in the "load and dynamic increase factors" in [14].

406 The use of a linear static approach in the DoD guidelines is restricted to structures without 407 "structural irregularities" as well as irregular structures in which the estimated demand-capacity 408 ratio from the linear analysis is less or equal than 2.0. Therefore this approach seems suitable for 409 the structure tested in this work. In the present study a linear static analysis was performed using 410 ANSYS software [55] to compare the experimental and numerical results in order to evaluate the 411 DAFs, as has been done in previous studies (e.g. Xiao et al. [42]). Beam elements (BEAM188 412 [55]) were adopted to simulate columns and shell elements (SHELL181 [55]) were considered 413 for slabs. The finite element model considered those mechanical and geometrical parameters of 414 the experimental test (See Section 2). A linear static analysis was carried out, without considering 415 dynamic amplification (DAF = 1.0). Fig. 19 shows the deformed shape (UY) of the finite element 416 (FE) model, before and after the sudden removal of the column. 

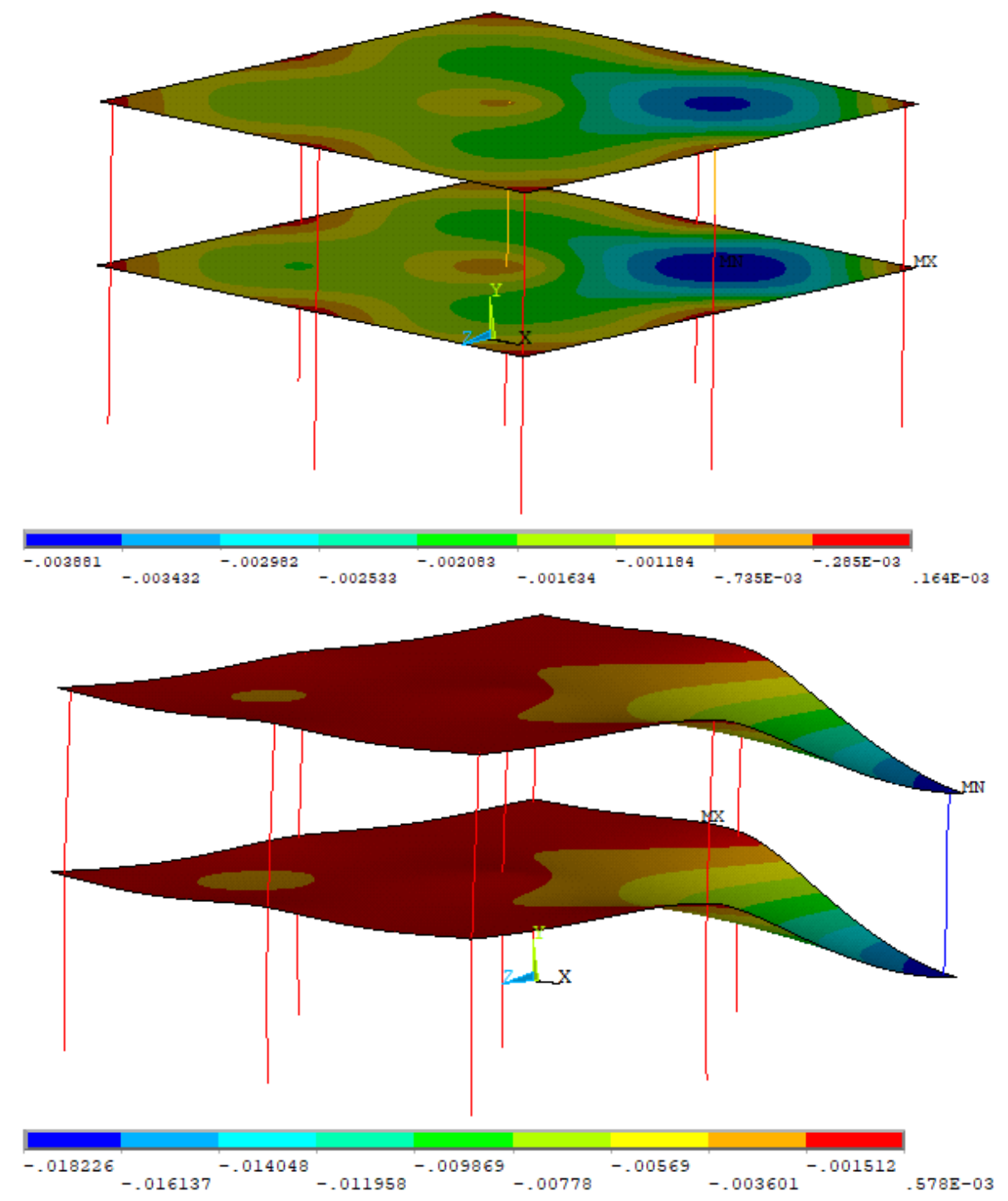

Fig. 19. UY deformed shape of the structure. Units in $m$.

Table 3 gives the experimental and numerical results obtained for the displacements (sensor LVDT_P3_11V) and axial force increment of columns P2 and P6. Table 3 provides the DAF

421 computed in this study, as the ratio between the dynamic value obtained experimentally (peak)

422 and the static value obtained numerically from the linear model (i.e. without introducing a

423 dynamic amplification factor). This ratio was computed for displacements $\left(\mathrm{DAF}_{\mathrm{LD}}\right)$ and axial 424 forces $\left(\mathrm{DAF}_{\mathrm{LF}}\right)$, following the definitions used in US DoD [14]. The dynamic axial force in the columns was estimated as the force prior to the column removal (estimated from the linear finite element analysis) plus the load increment obtained during the test after the column removal. 
Table 3. Dynamic load amplification factors for deformations and forces.

\begin{tabular}{cccc} 
& \multicolumn{2}{c}{ Displacement $[\mathrm{mm}]$} & \multirow{2}{*}{ DAF $_{\text {LD }}$} \\
\cline { 1 - 3 } Component & Experimental & Linear static analyses & 2.64
\end{tabular}

\begin{tabular}{|c|c|c|c|}
\hline \multicolumn{3}{|c|}{ Axial force increments $[\mathrm{kN}]$} & \multirow{2}{*}{$\begin{array}{c}\mathrm{DAF}_{\mathrm{LF}} \\
\text { (based on total axial forces) }\end{array}$} \\
\hline Component & Experimental & Linear static analysis & \\
\hline $\mathrm{P} 2$ & 187 & \multirow{2}{*}{107} & 1.25 \\
\hline P6 & 179 & & 1.23 \\
\hline Mean value & 183 & --- & 1.24 \\
\hline
\end{tabular}

429 As discussed in DoD [14] Annex C (commentary), following the definition above for the

430 DAFs leads to cases where inertial and nonlinear effects are combined. This leads for example to

431 a DAF LD $_{\text {larger than }} 2.0$ as shown in Table 3 which could be adopted in DoD as a load increase

432 factor (LIF) for a linear static analysis. Using a more refined (nonlinear) prediction of the static 433 displacement would result into $\mathrm{DAF}_{\mathrm{LD}}$ closer to 2.0 which is the theoretical dynamic amplification 434 in a 1-DOF linear system for a sudden applied load and no damping. It should be noted that the 435 LIF in DoD [14] may vary between 2.0 and 3.2 for two-way slabs and slab-column connections, depending on the ductility which is influenced by the presence of continuity reinforcement in the slab and the utilisation ratio of the punching shear strength in the connections.

The dynamic amplification factor for the axial loads in the columns $\mathrm{DAF}_{\mathrm{LF}}$ shown in Table 3 were around 1.24. These values are clearly below the value of 2.0 recommended by the DoD [14]

440 although it is recognised in Annex C of the guidelines that the Dynamic Increase Factor (DIF)

441 used for nonlinear static solutions is typically less than 2.0. In this case the static value of the axial 442 loads obtained from the linear analysis is relatively similar to the one obtained in a nonlinear 443 model and therefore the values of the $\mathrm{DAF}_{\mathrm{LF}}$ shown in Table 3 are a more truthful reflection of 444 the dynamic amplification. The values of the dynamic amplification of the load obtained in this 445 work $\left(\mathrm{DAF}_{\mathrm{LF}}=1.24\right)$ are also consistent with test results of sudden corner column removal by 446 Qian and Li [40] in which they report dynamic load increase factors between 1.13 and 1.23. These 447 results are also comparable with dynamic amplification factors for internal column removal 

and 1.2.

450

\section{Conclusions and future work}

This paper describes the study and analysis of an extensive experimental work carried out on a full-scale RC cast-in-place building structure subjected to a sudden corner-column failure scenario. This is the first study of this type (corner-column removal) on a full-scale building expressly built for the purpose subjected to representative loading used in design and provided with a comprehensive monitoring system. After describing the building itself, details are given on the test procedure and the monitoring system used. Real-time strain, displacement and acceleration results and alternative load paths (ALPs) are analysed, and a discussion is included of the overall response of the structure plus the dynamic amplification factors (DAFs). The results obtained allow the following conclusions to be drawn:

- The structure was able to find effective alternative load paths after the sudden removal of the corner-column, and the dynamic amplification observed did not resulted in extensive damage in the structure.

- The time-history test results showed that the peak dynamic values were significantly higher than the stabilized residual values after the test. The peaks reached values which were $16 \%, 71 \%$ and $400 \%$ higher over the residual values for the vertical displacements, strain in columns and horizontal displacements respectively.

- The predominant ALPs in the test were the flexural and Vierendeel beam actions, while slab membrane action was not a significant ALP for the case investigated. DoD guidelines [14] for load and dynamic increase factors. Regarding the vertical displacements, the values obtained for the load increase factor (combining inertial and nonlinear effects) were around 2.6 which was within the recommended values of 

dynamic increase factor were around 1.24 which is clearly below the standard value of 2.0 used in design. This confirms that adopting a simplified design value of 2.0 can lead to unrealistic assessment of damage for column removal situations. validation of dynamic punching shear models for slab-column connections under corner-column

480 removal scenarios. In the near future, the authors will carry out a similar test setup, combined 481 with numerical studies on the influence of masonry infill walls on the test results. The test results 482 shown in this paper can be used for validating future numerical models, verifying improved 483 clauses for robustness in design codes and help towards creating a larger database of full-scale building tests.

\section{Acknowledgements}

This work was carried out with the support of a 2017 Leonardo Grant for Researchers and Cultural Creators from the BBVA Foundation. The authors would also like to express their gratitude to the Levantina, Ingeniería y Construcción S.L. (LIC) company for funding the construction of the building.

\section{References}

[1] Adam JM, Parisi F, Sagaseta J, Lu X. Research and practice on progressive collapse and robustness of building structures in the 21st century. Eng Struct 2018;173:122-49. doi:10.1016/j.engstruct.2018.06.082.

[2] Dat PX, Tan KH. Experimental Response of Beam-Slab Substructures Subject to Penultimate-External Column Removal. J Struct Eng 2015;141:1-12.

[3] Qian K, Li B. Resilience of flat slab structures in different phases of progressive collapse.

[4] Fu F. Progressive collapse analysis of high-rise building with 3-D finite element modeling method. J Constr Steel Res 2009;65:1269-78. doi:10.1016/j.jcsr.2009.02.001. 
506 [6] Starossek U. Progressive Collapse of Structures. 2nd ed. Thomas Telford Ltd; 2018.

507 [7] Russell JM, Sagaseta J, Cormie D, Jones AEK. Historical review of prescriptive design rules for robustness after the collapse of Ronan Point. Structures 2019;20:365-73. doi:10.1016/j.istruc.2019.04.011.

510 [8] Starossek U. Typology of progressive collapse. Eng Struct 2007;29:2302-7. doi:10.1016/J.ENGSTRUCT.2006.11.025.

513

[9] Olmati P, Sagaseta J, Cormie D, Jones AEK. Simplified reliability analysis of punching in reinforced concrete flat slab buildings under accidental actions. Eng Struct 2017;130:83-98. doi:10.1016/j.engstruct.2016.09.061.

515

[10] Thiagarajan G, Kadambi A V., Robert S, Johnson CF. Experimental and finite element analysis of doubly reinforced concrete slabs subjected to blast loads. Int J Impact Eng 2015;75:162-73. doi:10.1016/j.ijimpeng.2014.07.018.

[11] Pham AT, Tan KH, Yu J. Numerical investigations on static and dynamic responses of reinforced concrete sub-assemblages under progressive collapse. Eng Struct 2017;149:220. doi:10.1016/j.engstruct.2016.07.042.

[12] Sagaseta J, Ulaeto N, Russell J. Structural robustness of concrete flat slab structures. ACI Struct J 2017;315:273-98.

[13] GSA. General Services Administration. Progressive collapse analysis and design guidelines for new federal office buildings and major organization projects; 2013.

[14] DoD. Department of Defense. Design of buildings to resist progressive collapse (UFC 4023-03); 2009.

[15] EN 1991-1-7. Eurocode 1: Actions on structures - Part 1-7: General actions - Accidental actions; 2006.

[16] Qian K, Weng YH, Li B. Impact of two columns missing on dynamic response of RC flat slab structures. Eng Struct 2018;177:598-615. doi:10.1016/j.engstruct.2018.10.011.

[17] Ren P, Li Y, Lu X, Guan H, Zhou Y. Experimental investigation of progressive collapse resistance of one-way reinforced concrete beam-slab substructures under a middlecolumn-removal scenario. Eng Struct 2016;118:28-40. doi:10.1016/j.engstruct.2016.03.051.

[18] Yi W-J, Kunnath SK, Zhang F-Z, Xiao Y. Large-scale experimental evaluation of building system response to sudden column removal. Struct. Congr., vol. 1, ASCE; 2011, p. 23537.

[19] Tohidi M, Baniotopoulos C. Effect of floor joint design on catenary actions of precast floor slab system. Eng Struct 2017;152:274-88. doi:10.1016/j.engstruct.2017.09.017.

[20] Kang SB, Tan KH. Progressive collapse resistance of precast concrete frames with discontinuous reinforcement in the joint. J Struct Eng 2017;143:1-13. doi:10.1061/(ASCE) ST.1943-541X.0001828.

[21] Al-Salloum YA, Alrubaidi MA, Elsanadedy HM, Almusallam TH, Iqbal RA. Strengthening of precast RC beam-column connections for progressive collapse mitigation using bolted steel plates. Eng Struct 2018;161:146-60. doi:10.1016/j.engstruct.2018.02.009.

[22] Almusallam TH, Elsanadedy HM, Al-Salloum YA, Siddiqui NA, Iqbal RA. Experimental Investigation on Vulnerability of Precast RC Beam-column Joints to Progressive Collapse. KSCE J Civ Eng 2018:1-16. doi:10.1007/s12205-018-1518-0.

550 [23] Sasani M, Sagiroglu S. Gravity load redistribution and progressive collapse resistance of 
20-story reinforced concrete structure following loss of interior column. ACI Struct J

[24] Jian H, Li S, Huanhuan L. Testing and Analysis on Progressive Collapse-Resistance Behavior of RC Frame Substructures under a Side Column Removal Scenario. J Perform Constr Facil 2016;30:1-7. doi:10.1061/(ASCE)CF.1943-5509.0000873.

[25] Qian K, Li B. Dynamic and residual behavior of reinforced concrete floors following instantaneous removal of a column. Eng Struct 2017;148:175-84. doi:10.1016/j.engstruct.2017.06.059.

[26] Peng Z, Orton SL, Liu J, Tian Y. Experimental Study of Dynamic Progressive Collapse in Flat-Plate Buildings Subjected to Exterior Column Removal. J Struct Eng 2017;143:113. doi:10.1061/(ASCE)ST.1943-541X.0001865.

[27] Kokot S, Anthoine A, Negro P, Solomos G. Static and dynamic analysis of a reinforced concrete flat slab frame building for progressive collapse. Eng Struct 2012;40:205-17. doi:10.1016/j.engstruct.2012.02.026.

[28] Bermejo M, Santos AP, Goicolea JM. Development of Practical Finite Element Models for Collapse of Reinforced Concrete Structures and Experimental Validation. Shock Vib 2017:1-9. doi:10.1155/2017/4636381.

[29] Lim NS, Tan KH, Lee CK. Experimental studies of 3D RC substructures under exterior and corner column removal scenarios. Eng Struct 2017;150:409-27. doi:10.1016/j.engstruct.2017.07.041.

[30] Stathas N, Bousias SN, Palios X, Strepelias E, Fardis MN. Tests and Simple Models of RC Frame Subassemblies for Postulated Loss of Column. J Struct Eng 2018;144:1-14. doi:10.1061/(ASCE)ST.1943-541X.0001951.

[31] Qian K, Li B. Performance of Precast Concrete Substructures with Dry Connections to Resist Progressive Collapse. J Perform Constr Facil 2018;32:1-14. doi:10.1061/(ASCE)CF.1943-5509.0001147.

[32] Fu Q, Tan K-H. Numerical study on steel-concrete composite floor systems under corner column removal scenario. Structures 2019. doi:10.1016/j.istruc.2019.06.003.

[33] Kai Q, Li B. Dynamic performance of RC beam-column substructures under the scenario of the loss of a corner column - Experimental results. Eng Struct 2012;42:154-67. doi:10.1016/j.engstruct.2012.04.016.

[34] Gao S, Guo L. Progressive collapse analysis of 20-storey building considering composite action of floor slab. Int J Steel Struct 2015;15:447-58. doi:10.1007/s13296-015-6014-5.

[35] Feng P, Qiang H, Ou X, Qin W, Yang J. Progressive Collapse Resistance of GFRPStrengthened RC Beam-Slab Subassemblages in a Corner Column-Removal Scenario. J Compos Constr 2019;23:1-15. doi:10.1061/(ASCE)CC.1943-5614.0000917.

[36] Zhang H, Shu G, Pan R. Failure Mechanism of Composite Frames Under the Corner Column-Removal Scenario. J Fail Anal Prev 2019;19:649-64. doi:10.1007/s11668-01900644-8.

[37] Ma F, Gilbert BP, Guan H, Xue H, Lu X, Li Y. Experimental study on the progressive collapse behaviour of RC flat plate substructures subjected to corner column removal scenarios. Eng Struct 2019;180:728-41. doi:10.1016/j.engstruct.2018.11.043.

[38] Qian K, Li B. Performance of Three-Dimensional Reinforced Concrete Beam-Column Substructures under Loss of a Corner Column Scenario. J Struct Eng 2013;139:584-94. doi:10.1061/(ASCE)ST.1943-541X.0000630. 
[39] Johnson ES, Meissner JE, Fahnestock LA. Experimental Behavior of a Half-Scale Steel Concrete Composite Floor System Subjected To Column Removal Scenarios. J Struct Eng 2013;142:1-12. doi:10.1061/(ASCE)ST.1943-541X.0001398.

[40] Qian K, Li B. Experimental study of drop panel effects on response of reinforced concrete flat slabs after loss of corner column. ACI Struct J 2013:845-56.

[41] Pham AT, Lim NS, Tan KH. Investigations of tensile membrane action in beam-slab systems under progressive collapse subject to different loading configurations and boundary conditions. Eng Struct 2017;150:520-36. doi:10.1016/j.engstruct.2017.07.060.

[42] Xiao Y, Kunnath S, Li FW, Zhao YB, Lew HS, Bao Y. Collapse Test of Three-Story HalfScale Reinforced Concrete Frame Building. ACI Struct J 2015;112:429-38. doi:10.14359/51687746.

[43] Xiao Y, Zhao YB, Li FW, Kunnath S, Lew HS. Collapse Test of a 3-Story Half-Scale RC Frame Structure. Struct Congr 2013:11-9. doi:10.1061/9780784412848.002.

[44] Zhang L, Zhao H, Wang T, Chen Q. Parametric Analysis on Collapse-resistance Performance of Reinforced-concrete Frame with Specially Shaped Columns Under Loss of a Corner Column. Open Constr Build Technol J 2016;10:466-80. doi: $10.2174 / 1874836801610010466$.

[45] Chen Q, Zhao H, Zhang L, Wang T. Progressive collapse resistance of reinforced-concrete frames with specially shaped columns under loss of a corner column. Mag Concr Res 2015;68:1-15. doi:10.1680/macr.15.00108.

[46] EN 1990. Eurocode: Basis of structural design; 2002.

[47] Russell JM, Owen JS, Hajirasouliha I. Experimental investigation on the dynamic response of RC flat slabs after a sudden column loss. Eng Struct 2015;99:28-41. doi:10.1016/j.engstruct.2015.04.040.

[48] EN 1992-1-1. Eurocode 2: Design of concrete structures - Part 1-1: General rules and rules for buildings; 2004.

[49] EN 1991-1-1. Eurocode 1: Actions on structures. Part 1-1: Densities, self-weight, imposed loads for buildings; 2003.

[50] Sasani M, Sagiroglu S. Progressive Collapse Resistance of Hotel San Diego. J Struct Eng 2008;134:478-88. doi:10.1061/(ASCE)0733-9445(2008)134:3(478).

[51] Yi W-J, He Q-F, Xiao Y, Kunnath SK. Experimental Study on Progressive CollapseResistant Behavior of Reinforced Concrete Frame Structures. ACI Struct J 2008;105:4339. doi:10.14359/19857.

[52] Black MS. Ultimate Strength Study of Two-Way Concrete Slabs. ASCE J Struct Div 1975;101:311-24.

[53] Rankin GIB, Long AE. Arching action strength enhancement in laterally-restrained slab strips. Proc Inst Civ Eng - Struct Build 1997;122:461-7. doi:10.1680/istbu.1997.29834.

[54] Park R, Gamble WL. Reinforced Concrete Slabs. 2nd ed. New York: John Wiley \& Sons, Inc; 2000.

[55] ANSYS 15.0. Theory reference. ANSYS Inc. 2014. 